\title{
Patricia Galeana [coord.], Historia comparada de las Américas, México, CIALC-CISAN-UNAM/IPGH, 2008, 593 pp.
}

Uno de los editores del libro que reseñamos es el Instituto Panamericano de Geografía e Historia (IPGH), del cual quiero hacer una breve referencia.

El IPGH es el organismo multilateral más antiguo de la región, fundado en 1928, e incorporado a la OEA desde hace varios años. Se dedica al estudio de la geografía e historia de América. Lo integran diversas comisiones, entre ellas la de historia, la cual a su vez, está conformada por varios comités, uno de ellos es el de Historia de la Cultura, creado y presidido durante muchos años por Leopoldo Zea.

Zea publicó infinidad de libros de diferentes temas vinculados a América como parte de las tareas de este Comité. Numerosos equipos internacionales se formaron a lo largo de medio siglo para investigar temas distintos de la historia y cultura de América. La colaboración que los intelectuales ofrecen al IPGH está llevada exclusivamente por un interés académico, pues no existe remuneración económica.

En 2004, a la muerte del Dr. Zea, la dirección del Comité pasó a la Dra. Patricia Galeana. Quiero expresar mi personal satisfacción por este hecho, no solamente por el dinamismo y capacidad que caracterizan su trabajo académico, sino porque, como es lógico, ha dado una nueva orientación a este Comité, además de un relevo generacional.

El primer trabajo que organizó fue precisamente un Seminario Internacional de Historia Comparada de las Américas, efectuado en la sede del Instituto, y cuyo resultado es este libro.

La obra tiene una introducción de su presidenta, Dra. Patricia Galeana, en la que hace una síntesis del proceso histórico de América con especial referencia al siglo XIX. La importancia del descubrimiento de América para el 
mundo de la época (no sólo el occidental) y las diferencias culturales que a lo largo del siglo xix comenzaron a conformar diferencias ontológicas, que al consumarse la independencia originaron las Américas, hispana católica, por una parte, y la anglosajona protestante, por la otra.

La introducción no sólo le da estructura a los diferentes ensayos que constituyen el libro, sino que destaca la importancia de hacer un análisis histórico comparativo.

La participación de diferentes especialistas de distintas regiones de América le ha dado mucha riqueza al volumen, ya que constituye un grupo multidisciplinario que hace interesantes aportaciones. He seleccionado algunos ensayos, pues la obra es muy extensa.

En el capítulo llamado "Mundos culturales: la idea del otro" haremos referencia a los distintos trabajos que lo integran.

1) En "La presencia del otro en la filosofía política contemporánea", de Paulette Dieterlen, se destaca el concepto de "el otro" en la historia de la filosofía. Analiza cómo la noción de identidad originó la conciencia de diferencia y propone un "liberalismo igualitario inclusivo", con un único límite que serían los derechos humanos y las obligaciones correspondientes apoyadas de la solidaridad basada en una idea racional de cooperación y ventajas mutuas, donde el diálogo entre personas de diferentes culturas puede convertir a "los otros" en "nosotros".

2) "La idea del otro en América y en México", de Enrique González Pedrero. Hace un examen de la tesis de Edmundo O'Gorman de que América no fue descubierta sino inventada por la cultura europea en 1492. Es un estudio muy riguroso de cada uno de los aspectos de este argumento y sus comentarios muy atinados.

3) "Multiculturalismo: consideraciones teóricas sobre la dimensión de lo lírico y la dimensión de lo ético", de Ignacio Díaz de la Serna.

Se trata de un análisis sobre la sociedad norteamericana, destaca cómo la tolerancia permitía al ciudadano eludir los temas religiosos y sobre todo la imposición de la religión de Estado. El principio de tolerancia ha estado siempre unido a las conquistas del liberalismo político estadounidense. En el actual Estados Uni- 
dos - nos dice-los conflictos no son religiosos sino étnicos y culturales. Se trata de un conflicto "multicultural" que carece de un fundamento territorial. La concepción republicana del multiculturalismo incluye la práctica de contabilizar razas y etnias, pero está desprovisto de connotaciones racistas intentando eliminar todo tipo de discriminación. El debate sobre la naturaleza de la nación americana comprende el tema de la "acción afirmativa", con las ventajas e inconvenientes que la misma conlleva. La igualdad de oportunidades no puede estar supeditada a consideraciones raciales porque se la considera antidemocrática.

La legitimidad de estos principios no están aclarados y menos aceptados unánimemente.

En el capítulo "Antecedentes históricos" destacamos los trabajos de:

1) Jorge Mario García Laguardia (Guatemala) quien escribe dos artículos: "Independencia, racionalismo e hispanoamericanismo", "El proyecto centroamericano de confederación", en este último hace un análisis histórico del proceso centroamericano en el siglo xIx y del desafortunado rompimiento de la República Federal Centroamericana.

2) Frank Moya Pons (Santo Domingo) quien relata un ensayo sobre el "El Caribe ante las Américas".

Es un interesante estudio de la plantación azucarera y su papel en la formación de las sociedades caribeñas, con unas características únicas por el establecimiento de la esclavitud africana. Estudia las relaciones de las 13 colonias británicas, hoy Estados Unidos, con el Caribe. La plantación como institución transplantada al Nuevo Mundo para facilitar la colonización y la explotación. Estudia cómo en el Caribe esta plantación y la esclavitud terminaron unidas.

Dentro del proceso caribeño da seguimiento a las relaciones con distintas colonias como las danesas, francesas, holandesas y el Caribe español. Destaca que la fragmentación caribeña no es el resultado de la geografía, sino de la dominación colonial.

El análisis de la explotación azucarera en Brasil le permite establecer las conexiones del Caribe con las Américas.

Por último quiero hacer un breve comentario al trabajo del historiador estadounidense James Petras. Para él es importante destacar la necesidad de 
plantear el desarrollo. Atribuye el retroceso de los últimos 25 años a la concentración de riquezas en sectores minoritarios que han traído como consecuencia luchas sociales en todo el continente.

La democracia - dice Petras-no es sólo cuestión de elecciones, sino de organización del poder social para asegurar un verdadero proceso de transformación. Pongo énfasis en que este análisis de Petras fue escrito antes de la crisis actual.

María ELENA RodRíGueZ OzÁN CIALC-UNAM 